\title{
Commentary: Pushing the limits: Robotic mitral valve surgery in cardiac dextroversion
}

\author{
Colin C. Yost, BA, Jake L. Rosen, BA, and \\ T. Sloane Guy, MD, MBA
}

We commend Bourdillon and colleagues ${ }^{1}$ on this case, which details the successful treatment of mitral regurgitation in a patient with cardiac dextroversion. We believe this report offers valuable insight into not only the recovery advantages of a robotic approach but also its ability to treat complex cardiac surgical pathologies that have traditionally required open intervention.

The approach to mitral valve repair has significantly evolved within the past several decades. Initial attempts at modern repair were influenced by Dr Alain Carpentier in $1983,{ }^{2}$ when he discussed mitral valve disease and the steps needed for safe and effective reconstruction. The approach to exposure at this time and for many subsequent years after was through median sternotomy, which allows for direct visualization and exposure to the entire heart and vessels. ${ }^{3}$ Dr Carpentier and his team reported favorable outcomes through open sternotomy, with strong freedom from cardiac-related morbidity and mortality in addition to low rates of reoperation. ${ }^{4}$

In recent years, surgeons have turned to less invasive alternatives, including minimally invasive mitral valve surgery (MIMVS) and robotic surgery to avoid open sternotomy while continuing to provide high quality results. ${ }^{3}$ MIMVS typically refers to operating through a right-sided

From the Division of Cardiovascular Surgery, Department of Surgery, Thomas Jefferson University, Philadelphia, Pa.

Disclosures: Dr Guy is a consultant for Edwards Lifesciences, Medtronic, and a case observation site and proctor for Intuitive Surgical. All other authors reported no conflicts of interest.

The Journal policy requires editors and reviewers to disclose conflicts of interest and to decline handling or reviewing manuscripts for which they may have a conflict of interest. The editors and reviewers of this article have no conflicts of interest.

$\mathrm{Mr}$ Yost and Mr Rosen contributed equally to this article.

Received for publication Nov 1, 2021; revisions received Nov 1, 2021; accepted for publication Nov 1, 2021; available ahead of print Nov 5, 2021.

Address for reprints: T. Sloane Guy, MD, MBA, Division of Cardiovascular Surgery, Department of Surgery, Thomas Jefferson University, 1025 Walnut St, Suite 607,

Philadelphia, PA 19107 (E-mail: sloane.guy@jefferson.edu).

JTCVS Techniques 2022;11:17-8

2666-2507

Copyright (c) 2021 The Author(s). Published by Elsevier Inc. on behalf of The American Association for Thoracic Surgery. This is an open access article under the CC BY-NC-ND license (http://creativecommons.org/licenses/by-nc-nd/4.0/).

https://doi.org/10.1016/j.xjtc.2021.11.003

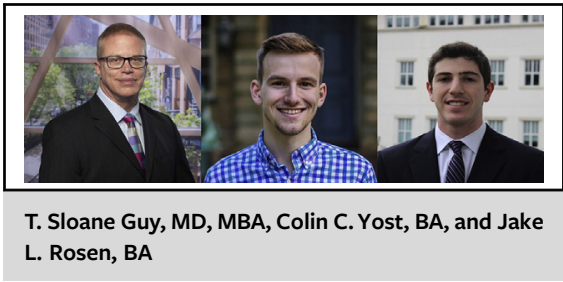

CENTRAL MESSAGE

Robotic surgery is a dynamic tool in the cardiac surgery armamentarium that can be adapted to an array of technically challenging patient pathologies and procedures while minimizing invasiveness.

minithoracotomy or ministernotomy. ${ }^{3}$ Robotic assistance is added by some to the minithoracotomy. Totally endoscopic robotic mitral valve surgery is performed with a robotically controlled endoscope and wristed remotely controlled instruments and an 8 to $30 \mathrm{~mm}$ working port without any rib spreading, an even less invasive approach than MIMVS. There are data to support shorter hospital stay lengths and noninferior postoperative outcomes in patients undergoing robotic versus normal repair. ${ }^{5}$ With an experienced team, robotic surgery can lead to a successful hospital course after mitral valve surgery without the need to open the chest.

Successful mitral valve repair in patients with dextroversion requires a complete understanding of the anatomic variations, such as the positioning of the pulmonary trunk relative to the aorta discussed by the authors. ${ }^{1}$ Furthermore, patients with dextroversion and situs solitus may also present with additional technical challenges such as univentricular systems and atrioventricular discordance. ${ }^{6}$ Its very interesting to see that the mitral valve is upside down compared with normal anatomy.

We would like to specifically highlight the adaptability of robotic port placement demonstrated by this case. At our center, ports for robotic mitral valve repair are typically placed on the patient's right side in approximately the third through seventh intercostal spaces in the right axilla to facilitate access to left atrium. However, the dextrocardia present in the authors' patient required port placement on the patient's left side, reversing the typical robotic approach to access the patient's reversed cardiac anatomy. Although 
cardiac dextroversion is quite rare, with an estimated incidence of approximately 1 in 12,000 pregnancies, $^{7}$ this case highlights the broader adaptability of robotic cardiac surgery, which allows the operative approach to be tailored to each patient's unique technical challenges.

The ultimate goal for surgical interventions beyond safety and efficacy is to minimize invasiveness and thus maximize patient satisfaction. As evidenced by the authors' successful completion of a complex robotic mitral valve repair in a patient with cardiac dextroversion, robotic cardiac surgery is a dynamic tool capable of achieving this goal. With adequate investment in the requisite equipment and personnel training, we believe the robotic approach offers a safe and effective means to usher in an era of minimally invasive cardiac surgery for the treatment of complicated pathologies that have traditionally required open surgery.

\section{References}

1. Bourdillon A, Elder R, Lalonde M, Steele J, Gruber PJ, Geirsson A. Robotic mitral valve repair in a patient with cardiac dextroversion. J Thorac Cardiovasc Surg Tech. 2022;11:12-6.

2. Carpentier A. Cardiac valve surgery-the "French correction." J Thorac Cardiovasc Surg. 1983;86:323-37. https://doi.org/10.1016/S0022-5223(19)39144-5

3. Glauber M, Miceli A. State of the art for approaching the mitral valve: sternotomy, minimally invasive or total endoscopic robotic? Eur J Cardiothorac Surg. 2015; 48:639-41. https://doi.org/10.1093/EJCTS/EZV312

4. Braunberger E, Deloche A, Berrebi A, Fayssoil A, Celestin JA, Melmoun P, et al. Very long-term results (more than 20 years) of valve repair with carpentier's techniques in nonrheumatic mitral valve insufficiency. Circulation. 2001;104(suppl 1): I8-11. https://doi.org/10.1161/CIRC.104.SUPPL_1.I-8-11

5. Cao C, Wolfenden H, Liou K, Pathan F, Gupta S, Nienaber TA, et al. A metaanalysis of robotic vs. conventional mitral valve surgery. Ann Cardiothorac Surg. 2015;4:305-14. https://doi.org/10.3978/J.ISSN.2225-319X.2014.10.05

6. Offen S, Jackson D, Canniffe C, Choudhary P, Celermajer DS. Dextrocardia in adults with congenital heart disease. Heart Lung Circ. 2016;25:352-7. https: //doi.org/10.1016/J.HLC.2015.09.003

7. Bohun CM, Potts JE, Casey BM, Sandor GGS. A population-based study of cardiac malformations and outcomes associated with dextrocardia. Am J Cardiol. 2007;100:305-9. https://doi.org/10.1016/J.AMJCARD.2007.02.095 